\title{
ICU-Acquired Weakness
}

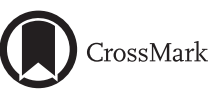

Sarah E. Jolley, MD; Aaron E. Bunnell, MD; and Catherine L. Hough, MD

Survivorship after critical illness is an increasingly important health-care concern as ICU use continues to increase while ICU mortality is decreasing. Survivors of critical illness experience marked disability and impairments in physical and cognitive function that persist for years after their initial ICU stay. Newfound impairment is associated with increased health-care costs and use, reductions in health-related quality of life, and prolonged unemployment. Weakness, critical illness neuropathy and/or myopathy, and muscle atrophy are common in patients who are critically ill, with up to $80 \%$ of patients admitted to the ICU developing some form of neuromuscular dysfunction. ICU-acquired weakness (ICUAW) is associated with longer durations of mechanical ventilation and hospitalization, along with greater functional impairment for survivors. Although there is increasing recognition of ICUAW as a clinical entity, significant knowledge gaps exist concerning identifying patients at high risk for its development and understanding its role in long-term outcomes after critical illness. This review addresses the epidemiologic and pathophysiologic aspects of ICUAW; highlights the diagnostic challenges associated with its diagnosis in patients who are critically ill; and proposes, to our knowledge, a novel strategy for identifying ICUAW.

CHEST 2016; 150(5):1129-1140

KEY WORDS: critical illness myopathy; critical illness polyneuropathy; ICU-acquired weakness; ICU neuromuscular dysfunction; ICU rehabilitation

\section{Epidemiology of ICU-Acquired Weakness}

Neuromuscular abnormalities long have been described in connection with critical illness. In 1892, Sir William Osler reported "rapid loss of flesh" in patients with prolonged sepsis. ${ }^{1}$ Mertens ${ }^{2}$ described polyneuropathy in patients in a coma in the 1960s; in 1977, evidence of acute myopathy was reported in a patient with status asthmaticus. $^{3-5}$ In 2002, De Jonghe et $\mathrm{al}^{6}$ reported an incidence of ICU-acquired paresis, as measured by means of a Medical Research Council (MRC)-graded manual muscle strength score $<48$ (consistent with severe weakness reflecting inability to resist gravity) in $25.3 \%$ (24 of 95) of patients receiving mechanical ventilation for $\geq 7$ days who survived to awakening and could follow commands. Electrophysiology
ABBREVIATIONS: ADL = activity of daily living; $\mathrm{CIM}=$ critical illness myopathy; CIP = critical illness polyneuropathy; CMAP = compound motor action potential; EMG = electromyography; $\mathrm{EP}=$ electrophysiology; ICUAW = ICU-acquired weakness; $\mathrm{MRC}=$ Medical Research Council; NCS = nerve conduction study; NMB = neuromuscular blockade; PFIT = Physical Function ICU Test; PFS = Physical Functioning Scale; RCT = randomized controlled trial; SF-36 = Short-Form 36; SNAP = sensory nerve action potential

AfFiliations: From the Section of Pulmonary/Critical Care Medicine and Allergy/Immunology (Dr Jolley), Louisiana State University Health Sciences Center, New Orleans, LA; and the Department of Rehabilitation Medicine (Dr Bunnell) and the Division of Pulmonary and Critical Care Medicine (Dr Hough), Harborview Medical Center, University of Washington, Seattle, WA.
FUNDING/SUPPORT: S. E. J. is supported in part by the National Institute of General Medical Sciences of the National Institutes of Health [Grant 1 U54 GM104940], which funds the Louisiana Clinical and Translational Science Center. The content is solely the responsibility of the authors and does not necessarily represent the official views of the National Institutes of Health.

CORRESPONDENCE TO: Catherine L. Hough, MD, Harborview Medical Center, 325 Ninth Ave, Seattle, WA 98104; e-mail: cterrlee@uw.edu Copyright (C) 2016 American College of Chest Physicians. Published by Elsevier Inc. All rights reserved.

DOI: http://dx.doi.org/10.1016/j.chest.2016.03.045 
(EP) testing performed in all patients with persisting weakness showed reduced compound motor action potentials (CMAPs) and sensory nerve action potentials (SNAPs) with abnormal spontaneous muscle activityconsistent with sensorimotor axonal peripheral neuropathy. Subsequent review of muscle biopsy specimens in 10 patients demonstrated type II fiber atrophy with myosinolysis consistent with primary myopathy and neurogenic muscle atrophy.

These early studies suggest that severe weakness is common in patients who are critically ill, particularly those with prolonged durations of ventilation.

Furthermore, objective neuromuscular changes may be more prevalent than is clinically measurable weakness, and studies suggest that these neuromuscular changes may impact outcomes adversely. ${ }^{7,8}$ Among 730 patients with respiratory failure, the presence of an abnormal CMAP on day 8 of ventilation was associated with a $20.4 \%$ higher 1-year mortality, with a significant difference in the absence of demonstrable weakness (MRC > 48; 1-year mortality, 48.2\% [group with abnormal CMAP] vs $29.3 \% ; P=.010){ }^{7}$ Therefore, the impact of these occult neuromuscular changes on longer-term function and outcomes may be greater than previously understood.

\section{Pathophysiology of ICU-Acquired Weakness}

ICU-acquired weakness (ICUAW) in patients who are critically ill commonly manifests in three ways: polyneuropathy, myopathy, and/or muscle atrophy. ${ }^{6}$ Neuromuscular dysfunction is identified using EP testing. Motor (commonly the peroneal) and sensory (commonly the sural) nerves are stimulated (Fig 1) with increasing stimulus to elicit distal muscle depolarization. Abnormalities in the resultant action potential result from either nerve or muscle injury or a combination of both.

Critical illness polyneuropathy (CIP) is characterized by a symmetric, distal sensory-motor axonal

polyneuropathy affecting limb and respiratory muscles, as well as sensory and autonomic nerves. ${ }^{9-11}$ EP studies demonstrate abnormal sensory and motor responses with a reduction in the CMAP and SNAP amplitudes. Despite abnormal nerve conduction study (NCS) results, histologic analysis of sensory nerves in patients with CIP generally appear normal early in the course of illness, with axonal degeneration evident only late in the course. ${ }^{10}$ Direct muscle stimulation with a stimulating needle electrode demonstrates preserved CMAP

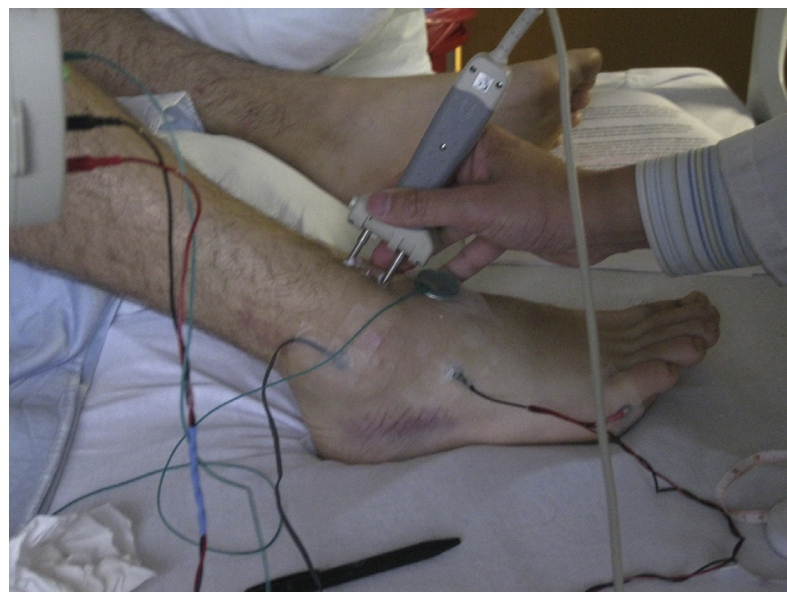

Figure 1 - Single fibular nerve conduction study. In a patient who is supine and normothermic, the recording active electrode (black) is placed over the extensor digitorum brevis muscle. The reference electrode (red) is placed over the fifth metatarsalphalangeal joint. Stimulation occurs $8 \mathrm{~cm}$ proximal to the active electrode, slightly lateral to the tibialis anterior tendon. Ground electrode (green) is placed between the stimulation site and the recording active electrode.

amplitude differentiating neuropathy from myopathy. Needle electromyography (EMG) may demonstrate short-term changes associated with axonal loss and reduced recruitment. A number of theories have emerged regarding the cause of the development of CIP, including loss of the blood-nerve barrier, inexcitability of the endoneurial membrane, and direct toxic effects from ICU therapies including hyperglycemia or lipids in parenteral nutrition. ${ }^{?}$

Critical illness myopathy (CIM) is characterized by limb and respiratory muscle weakness with retained sensory function. EP testing demonstrates reduced CMAP amplitudes with preservation of sensory responses. Needle EMG may demonstrate short-term changes and, if the patient is able to participate, myopathic motor unit action potentials. Direct muscle stimulation may demonstrate low-amplitude CMAP from both muscle and nerve. Histologic study of muscle biopsy specimens demonstrates atrophy with preferential loss of thick filaments reflecting myosin loss and muscle necrosis. ${ }^{10}$ Proposed causes for the muscle destruction seen in CIM include chemokine-induced autophagy of muscle, muscle membrane inexcitability, acquisition of channelopathies, or direct toxic effects of ICU care including corticosteroids or neuromuscular blockade (NMB). ${ }^{9}$

It is increasingly recognized that muscle atrophy, CIM, and CIP are not necessarily distinct entities but likely are an overlapping spectrum triggered by an acute inflammatory response, often occurring simultaneously. 
Therefore, ICUAW phenotypes vary among patients who are critically ill, and ICUAW diagnostic testing relies on varying stages of patient participation, making prevalence studies difficult. These limitations impair our ability to estimate the overall burden of ICUAW precisely in patients who are critically ill.

\section{Current Limitations in Identification of ICUAW}

When Bolton et $\mathrm{al}^{12}$ first described polyneuropathy acquired during critical illness in the early 1980s, they relied heavily on EP testing and muscle biopsy to define the clinical syndromes. Current diagnostic criteria for CIM and CIP require EP testing to demonstrate reductions in CMAPs and SNAPs and histologic evidence for full diagnosis of CIM. ${ }^{10,13}$ In reality, at the bedside, performing complete neurophysiologic testing or muscle biopsy in patients who are critically ill remains challenging. The presence of tissue edema and electrical interference theoretically reduces the accuracy of NCSs in patients in the ICU, although the extent to which these concerns affect diagnosis is unknown. Coagulopathy, lack of trained pathologists for interpretation, cost, and patient refusal because of pain limit the utility of routine muscle biopsy. Additionally, abnormalities may be identified in the vast majority of subjects who are critically ill, ${ }^{14}$ suggesting these studies may discriminate poorly between occult and clinically relevant disease.

Given the limitations in specialized diagnostics (Table 1) for ICUAW, investigators have suggested the field should adopt a clinical diagnosis. ${ }^{15}$ ICUAW is diagnosed clinically by using a standardized, validated measure such as the manual muscle strength test to quantify muscle weakness. Although strength testing accurately indicates clinically important weakness in up to $25 \%$ of patients who are critically ill, a minority of patients (29\%) in these studies achieved spontaneous awakening to participate in testing. ${ }^{6}$ Identifying patients who are awake and cooperative in the ICU is challenging. Among 135 patients with acute respiratory failure in a

TABLE 1$]$ Benefits and Limitations to Currently Available Modalities for Identifying ICU-Acquired Neuromuscular Dysfunction

\begin{tabular}{|c|c|c|}
\hline Modality & Potential Benefits & Potential Limitations \\
\hline Full NCSs with EMG & $\begin{array}{l}\text { - Part of the gold standard definition of CIM } \\
\text { and CIP } \\
\text { - Associated with functional outcomes }\end{array}$ & $\begin{array}{l}\text { - Time intensive } \\
\text { - Expensive } \\
\text { - Moderately invasive } \\
\text { - Requires technical expertise } \\
\text { - Potentially limited by tissue edema or } \\
\text { electrical interference } \\
\text { - Requires patient participation for full EMG }\end{array}$ \\
\hline Single NCSs & $\begin{array}{l}\text { - Quick to perform } \\
\text { - Minimally invasive } \\
\text { - Less cost than full NCS } \\
\text { - Associated with functional outcomes }\end{array}$ & $\begin{array}{l}\text { - Requires technical expertise } \\
\text { - Potentially limited by tissue edema or } \\
\text { electrical interference }\end{array}$ \\
\hline Muscle biopsy & $\begin{array}{l}\text { - Depicts muscle architecture } \\
\text { - Differentiates CIM from CIP } \\
\text { - Part of gold standard for diagnosis of CIM }\end{array}$ & $\begin{array}{l}\text { - Invasive } \\
\text { - Expensive } \\
\text { - Potentially painful } \\
\text { - Requires technical expertise } \\
\text { - Requires pathologist support for } \\
\text { interpretation } \\
\text { - Patient refusal common } \\
\text { - Risk of bleeding and/or infection }\end{array}$ \\
\hline Muscle ultrasound & $\begin{array}{l}\text { - Depicts gross muscle architecture } \\
\text { - Noninvasive and comfortable for the patient } \\
\text { - Does not require patient participation } \\
\text { - Inexpensive once ultrasound machine is } \\
\text { obtained } \\
\text { - Good interrater reliability } \\
\text { - Readily available in most ICU settings }\end{array}$ & $\begin{array}{l}\text { - Requires technical expertise } \\
\text { - Diagnostic accuracy and functional } \\
\text { significance for CIM and CIP not yet clear } \\
\text { - May be limited in patients who are obese } \\
\text { or severely edematous }\end{array}$ \\
\hline $\begin{array}{l}\text { MRC manual muscle } \\
\text { strength testing }\end{array}$ & $\begin{array}{l}\text { - Easy to administer } \\
\text { - Minimal expertise necessary } \\
\text { - Cheap } \\
\text { - Direct functional significance }\end{array}$ & $\begin{array}{l}\text { - Relies on patient cooperation } \\
\text { - Interrater variation } \\
\text { - Ceiling effect after hospital discharge }\end{array}$ \\
\hline
\end{tabular}

$\mathrm{CIM}=$ critical illness myopathy; CIP = critical illness polyneuropathy; EMG = electromyography; MRC = Medical Research Council; NCS = nerve conduction study. 
single center, $75 \%$ were unable to participate in MRC testing ${ }^{16}$ because of coma, delirium, and traumatic injury early in the course of critical illness. Beyond patient participation, there is significant interobserver variation in the MRC scale. A study of manual muscle strength testing by two experienced physiotherapists showed only moderate interobserver agreement $(\kappa, 0.60) .{ }^{17}$ In a cohort restricted to patients who were cooperative, MRC testing performed better, with very good interobserver agreement (intraclass correlation, 0.95 ) when performed by trained physiotherapists. ${ }^{18}$ However, these concerns limit routine MRC manual muscle strength testing in the diagnosis of ICUAW, particularly early in the course of critical illness.

Some studies propose that handgrip strength measured by means of handgrip dynamometry may be useful as an alternative measure of global muscle strength in patients who are critically ill. In a prospective study of patients with respiratory failure, dynamometry helped diagnose ICUAW with a sensitivity of $80.6 \%$, specificity of $82.4 \%$, and negative predictive value of $91.3 \%$ when compared with MRC testing as a gold standard. ${ }^{19}$ This study also showed a significant independent association between low handgrip strength and mortality. However, such studies are limited by the same aforementioned limitations given the use of the MRC scale as the gold standard comparison, making the exact role of handgrip dynamometry uncertain.

\section{Additional Diagnostic Approaches to Identify ICUAW}

Prompt, routine diagnosis of ICUAW in patients who are critically ill is hindered by the absence of a reliable, easily obtainable screening test in patients who are comatose. EP assessment and muscle biopsy are not employed routinely in clinical practice, and manual muscle strength testing requires a patient who is participatory. Studies of incidence, risk factors, and outcomes of ICUAW are impaired by the inability to make consistent diagnoses.

Limited NCSs show promise as a sole diagnostic test for ICU-acquired neuromuscular dysfunction. ${ }^{8}$ This test is quick, safe, and easy to administer. The common peroneal (fibular) CMAP is measured using two surface electrodes, with the active electrode placed on the belly of the extensor digitorum brevis muscle and the reference electrode placed on the distal tendon of the recorded muscle (Fig 1). ${ }^{20}$ The peroneal nerve is stimulated over the dorsum of the foot near the ankle, with increasing stimulus intensity until maximal CMAP is achieved. Latronico et $\mathrm{al}^{20}$ validated this procedure in a multicenter cohort of patients who were critically ill. Comparing single peroneal NCS with complete NCS-EMG studies, the single nerve study was $100 \%$ sensitive (95\% CI, 96.1\%-100\%) for the diagnosis of polyneuropathy and myopathy, with a specificity of 85.2\% (95\% CI, 66.3\%-95.8\%). Similarly, Moss et $\mathrm{al}^{8}$ reported that peroneal and sural sensory NCS yielded a sensitivity of $100 \%$ (95\% CI, 100\%-100\%; c-statistic, 0.9336 ) for neuromyopathy, with a specificity of $81 \%$ (95\% CI, 71\%-91\%). Diagnostic accuracy appears improved with the use of cutoffs derived from subjects with ICUAW rather than healthy control subjects (specificity of $75 \%$ in ICUAW vs $36 \%$ in healthy control subjects). ${ }^{21}$ These results suggest that isolated lower extremity NCS may be adequate for diagnosis of ICUAW. Although EP studies may be useful in the diagnosis of ICUAW, therapeutic utility is limited. Currently, no therapeutic options for ICUAW exist that alter EP findings, making it unlikely that routine use in clinical care would impact routine outcomes.

Point-of-care ultrasound is an essential diagnostic tool in modern ICUs, and quantitative neuromuscular ultrasound increasingly is being evaluated as a research tool for identification of muscle atrophy. ${ }^{22}$ In a study of 63 patients who were critically ill, cross-sectional area measurement by means of ultrasound of the rectus femoris muscle demonstrated early, rapidly progressive muscle loss averaging a $10 \%$ loss in cross-sectional area over the first week of respiratory failure. ${ }^{23}$ In another cohort of patients with respiratory failure, vastus lateralis ultrasound had a sensitivity of $74 \%$ for prediction of myofiber necrosis in muscle biopsy specimens; in patients without a potential iatrogenic cause for muscle necrosis, sensitivity increased to $85 \% .{ }^{24}$ Among patients with sepsis, muscle ultrasound was able to help detect neuromyopathy in $93 \%$ of patients studied, with excellent interrater reliability (intraclass correlation, 0.97). ${ }^{24}$ Although muscle ultrasound is a potential noninvasive marker of ICUAW, we currently lack evidence demonstrating an association between ultrasound findings and clinical outcomes and therapeutic ultrasound targets, limiting routine clinical use.

\section{Risk Factors for Development of ICUAW \\ Premorbid Health as a Potential Risk Factor}

To date, most studies of weakness, atrophy, myopathy, and neuropathy seen during and after critical illness 
make the assumption that these abnormalities are ICU acquired, stemming from direct effects of critical illness or sequelae of short-term interventions. However, studies of ICUAW are limited by a lack of baseline neuromuscular assessment, and, to our knowledge, no studies to date attempt to control for prehospital muscle function or overall functional status as a predictor of ICUAW.

Sarcopenia is the age-related loss of muscle mass constituting part of the frailty syndrome, a complex disease process characterized by loss of cognitive and physical reserve in elderly adults. ${ }^{25}$ Investigations suggest that up to $81 \%$ of elderly patients in the ICU, in the absence of known ICUAW, met frailty criteria. ${ }^{26}$ Patients who were frail and older experienced a threefold increase in ICU mortality and an increased risk of death in the 6 months after critical illness. ${ }^{27}$ In nonelderly individuals, clinically defined frailty was associated with an $80 \%$ increase in the odds of in- and posthospital ( $<6$ months) death, with an increasing frailty score correlating with death in a linear dose-response fashion. ${ }^{26}$ In patients surviving critical illness, frailty appears to be an important predictor of long-term morbidity. ${ }^{26,28}$ Patients with identified frailty who survived critical illness were $22 \%$ less likely to be living at home independently during the year after critical illness and reported significantly worse health-related quality of life than did nonfrail survivors of critical care or the general population. ${ }^{26,28}$ Studies are needed that examine the role of frailty specifically in subjects with known ICUAW to understand its impact on ICUAW outcomes.

In studies of survivors of severe sepsis with available prehospital data, pre-illness function was an independent predictor of incremental loss in function and associated cognitive decline. ${ }^{29}$ Analysis of patients with years of prehospital functional data subsequently admitted for severe sepsis demonstrated that many of the symptoms of the post-ICU syndrome commonly were present before admission. ${ }^{30}$ Accounting for the prehospital functional trajectory appeared to define the care trajectory after critical illness better. ${ }^{30}$ These data highlight the increasing recognition that prehospital function informs in- and posthospital impairments and the variance in ICUAW phenotypes that may respond differentially to ICU interventions.

\section{In-Hospital Risk Factors for ICUAW}

Despite dozens of studies looking at clinical risk factors for ICUAW, there is still little certainty of which factors are truly causal. The most consistently implicated risk factors are those associated with severity of illness, including shock, sepsis, and degree of multiple organ failure. ${ }^{6,20,31,32}$ This supports the premise that ICUAW is actually another manifestation of the multiple organ dysfunction syndrome. ${ }^{31,33}$ Cohort studies in patients who are critically ill show an association between sepsis and ICUAW in unadjusted analyses with estimated ORs varying between 2.9 and $49 .^{15}$

A number of ICU interventions or exposures are identified as potential risk factors for ICUAW. These include administration of corticosteroids or NMB, glycemic control, aminoglycoside therapy, and immobilization. There are conflicting data on the associations between corticosteroids and NMB with ICUAW. ${ }^{6,34-40}$ Unadjusted analyses ${ }^{4,34,40}$ in patients who are critically ill suggest an increased frequency of ICUAW in patients receiving corticosteroids, and a single multivariable analysis reported increased risk of paresis in patients exposed to steroids (OR, 14.90; 95\% CI, 3.20-69.80; $P<.001){ }^{6}$ Additional multivariable analyses including one randomized controlled trial (RCT) secondary analysis, however, failed to show an association between corticosteroids and ICUAW. ${ }^{31,33,41}$ The overall effect of corticosteroids on ICUAW remains uncertain and difficult to ascertain because of indication bias, high variability in patient phenotypes, and steroid dosing. Although steroids act as direct nerve and muscle toxins, they also are associated with reduced inflammation and severity of illness, which may decrease risk for ICUAW. Likewise, small unadjusted analyses suggest increased frequency of ICUAW in patients receiving NMB agents. ${ }^{37,42}$ Adjusted analyses, however, failed to show an independent association of NMB with development of ICUAW, ${ }^{6,31}$ and a single RCT of early NMB use in patients with ARDS showed no significant difference in development of ICUAW. ${ }^{43}$ Like steroids, early NMB may result in decreases in other better established risk factors, including severity of illness or organ dysfunction and duration of mechanical ventilation.

In an RCT, intensive insulin therapy decreased abnormal spontaneous activity at EMG, suggesting that more insulin and less hyperglycemia may reduce ICUAW. ${ }^{44}$ Aminoglycoside antibiotics were associated with paresis in a single study; however, additional observational studies demonstrated no significant association. ${ }^{6,34,36,39,40}$ There are single studies suggesting that other potentially modifiable ICU interventions, including liberal fluid administration and transfusion, 
may contribute to ICUAW, although these associations need verification in larger patient cohorts. ${ }^{45,46}$

Prolonged immobilization is associated with atrophy in patients who are critically ill. Muscle disuse is associated with changes in muscle diameter, length, and contractile strength. ${ }^{4-50}$ These changes may result in increasing muscle atrophy as the duration of immobility is prolonged. In healthy subjects, muscles show sarcomere reduction and fiber shortening within 4 hours of immobilization. ${ }^{47,48}$ After 1 week of complete immobilization in healthy volunteers, postural muscle strength is reduced by $5 \%$ to $10 \%$, with an average daily loss of $1 \%$ to $1.3 \%$ of overall muscle strength. ${ }^{51,52}$ This reduction may be exacerbated further by critical illness. In an observational cohort of 109 patients with ARDS, survivors experienced $18 \%$ reductions in their baseline body weight on average at hospital discharge. ${ }^{53}$ Immobilization, therefore, may be an early identifiable, modifiable risk factor for targeted interventions. Studies are needed to determine whether identification and modification of such risk factors early in the course of critical illness contributes to reductions in prevalence of ICUAW.

\section{ICUAW, Mortality, and Long-term Physical Function}

An increasing number of studies highlight the burden of impairment seen after critical illness, particularly after ARDS, but few attempt to link ICUAW with subsequent morbidity and mortality. ICUAW is an increasingly recognized independent predictor of mortality in patients who are critically ill. In a propensity-matched cohort of patients who were critically ill, MRC-defined ICUAW was associated with a $30 \%$ lower likelihood of being alive at hospital discharge (hazard ratio, 0.70; $95 \%$ CI, $0.55-0.86 ; P=.008$ ), with a $13 \%$ increase in mortality at 1 year. ${ }^{54}$ This finding supports those of prior observational studies, suggesting increased odds of death associated with ICUAW independent of other ICU factors. ${ }^{19,55}$

Although it seems intuitive that ICUAW would impact long-term physical function after critical illness, few data support this assumption to date. In the Improving Care of Acute Lung Injury Patients study, Fan et a ${ }^{56}$ examined the association between ICUAW (defined as an MRC strength score $<80 \%$ maximum) with postdischarge strength measured by means of serial testing at 3,6,12, and 24 months after ARDS. In the cohort, $36 \%$ of patients exhibited signs of ICUAW at hospital discharge, with the prevalence decreasing to $22 \%$ at 3 months, $15 \%$ at 6 months, $14 \%$ at 12 months, and $9 \%$ at 24 months after ARDS. ${ }^{56}$ Manual muscle strength increased significantly over time, with an increase in total MRC score from 50 at hospital discharge to 57 at 24 months. ${ }^{56}$ Despite improvements in overall strength, physical functioning health-related quality-of-life subscales remained significantly lower than age-adjusted norms at all time points, achieving only $72 \%$ of baseline values at 24 months. ${ }^{56}$ Patients with documented ICUAW maintained significantly worse handgrip strength and reported worse physical functioning health-related quality of life.

Similarly, in a cohort of survivors of critical illness, Wieske et $\mathrm{al}^{57}$ noted that patients receiving mechanical ventilation who developed MRC-defined ICUAW experienced significantly lower physical functioning health-related quality of life (median Short-Form 36 [SF-36] Physical Functioning Score [PFS] of 45 [interquartile range, 30-79] vs 75 [interquartile range, 50-90]; $P \leq .01)$ compared with patients who were not weak at 6 months after illness. Higher strength scores were correlated significantly with higher PFS. ICUAW was associated with a 16.7-point decrease in PFS after covariate adjustment. ${ }^{57}$ Further studies are needed to understand the long-term impact of ICUAW on the burden of impairment seen after critical illness.

\section{Interventions Aimed at Reducing ICUAW}

Therapeutic options for prevention or treatment of ICUAW remain limited. Table 2 presents a summary of prevention and intervention studies in patients with or at risk for ICUAW. Secondary analyses of an RCT of intensive insulin therapy (blood sugar levels between 80 and $110 \mathrm{mg} / \mathrm{dL}$ ) suggested more stringent glucose control was associated with lower rates of ICUAW. Intensive insulin therapy, however, also was associated with increased rates of life-threatening hypoglycemia, leading most clinicians to abandon the practice. ${ }^{44,59}$

There is building literature regarding early exercise to maintain muscle strength and improve function in patients in the ICU. Prospective cohort studies in patients with acute respiratory failure showed that mobility in patients receiving mechanical ventilation was safe, feasible, and associated with reductions in length of stay and mortality. ${ }^{61,66-68}$ An RCT in patients performing activity through physical or occupational therapy within 48 hours of respiratory failure showed improvement in activities of daily living (ADLs) 
TABLE 2 ] Summary of Interventions Aimed at Reducing ICU-Acquired Neuromuscular Dysfunction

\begin{tabular}{|c|c|c|c|}
\hline Study/Year & Study Design/Cohort & Interventions & Outcomes \\
\hline $\begin{array}{l}\text { Griffiths } \\
\text { et } \mathrm{al}^{58} / 1995\end{array}$ & $\begin{array}{l}\text { Prospective cohort study } \\
\text { in patients receiving } \\
\text { neuromuscular blockade } \\
\text { for }>7 \text { days }(n=5)\end{array}$ & $\begin{array}{l}\text { Between-leg comparison of 3-h } \\
\text { continuous passive motion } \\
\text { daily with no therapy }\end{array}$ & $11 \%$ mean increase in fiber area \\
\hline $\begin{array}{l}\text { van den } \\
\text { Berghe } \\
\text { et } \mathrm{al}^{44} / 2001\end{array}$ & $\begin{array}{l}\text { Prospectively planned } \\
\text { subgroup analysis of RCT } \\
(\mathrm{n}=1,200)\end{array}$ & $\begin{array}{l}\text { Intensive insulin vs standard } \\
\text { insulin therapy }\end{array}$ & $\begin{array}{l}\text { Decrease in critical illness } \\
\text { polyneuropathy by } 49 \% \text {, increase } \\
\text { in life-threatening hypoglycemia }\end{array}$ \\
\hline $\begin{array}{l}\text { Hermans } \\
\text { et } \mathrm{al}^{59} / 2009\end{array}$ & $\begin{array}{l}\text { Secondary analysis of RCT in } \\
\text { patients requiring at least } \\
7 \text { days of mechanical } \\
\text { ventilation }(n=420)\end{array}$ & $\begin{array}{l}\text { Intensive insulin therapy } \\
\text { vs standard insulin therapy }\end{array}$ & $\begin{array}{l}\text { Reduction in critical illness } \\
\text { polyneuropathy of } 11.6 \%\end{array}$ \\
\hline $\begin{array}{l}\text { Burtin et } \mathrm{al}^{60} / \\
\quad 2009\end{array}$ & $\begin{array}{l}\text { RCT in patients who were } \\
\text { critically ill with expected } \\
\text { stay of } 7 \text { days }(n=90)\end{array}$ & $\begin{array}{l}\text { 20-min bedside ergometer use } \\
\text { vs usual care }\end{array}$ & $\begin{array}{l}\text { Greater 6MWD, SF-36 physical } \\
\text { functioning score, and quadriceps } \\
\text { force at hospital discharge }\end{array}$ \\
\hline $\begin{array}{l}\text { Morris et } \mathrm{al}^{61} / \\
2008\end{array}$ & $\begin{array}{l}\text { Prospective cohort study in } \\
\text { patients with acute } \\
\text { respiratory failure in the } \\
\text { medical ICU }(n=330)\end{array}$ & $\begin{array}{l}\text { Progressive mobility protocol } \\
\text { vs usual care }\end{array}$ & $\begin{array}{l}\text { Reduction in ICU and hospital length } \\
\text { of stay }\end{array}$ \\
\hline $\begin{array}{l}\text { Schweickert } \\
\text { et } \mathrm{al}^{62} / 2009\end{array}$ & $\begin{array}{l}\text { RCT in patients with acute } \\
\text { respiratory failure in the } \\
\text { medical ICU }(n=104)\end{array}$ & $\begin{array}{l}\text { Early physical and occupational } \\
\text { therapy vs usual care }\end{array}$ & $\begin{array}{l}\text { Increase in ambulation status and } \\
\text { activities of daily living } \\
\text { independence, reduction in } \\
\text { delirium and in ICU and hospital } \\
\text { length of stay, trend toward } \\
\text { improved muscle strength }\end{array}$ \\
\hline $\begin{array}{l}\text { Angelopoulos } \\
\text { et } \mathrm{al}^{63} / 2013\end{array}$ & $\begin{array}{l}\text { RCT in patients who were } \\
\text { critically ill with and } \\
\text { without neuromyopathy } \\
(\mathrm{n}=31)\end{array}$ & $\begin{array}{l}\text { Neuromuscular stimulation } \\
\text { using high }(75 \mathrm{~Hz}) \text { or medium } \\
(45 \mathrm{~Hz}) \text { frequency for } 30 \mathrm{~min}\end{array}$ & $\begin{array}{l}\text { Increased oxygen consumption, } \\
\text { endothelial reactivity, and vascular } \\
\text { reserve }\end{array}$ \\
\hline $\begin{array}{l}\text { Kho et } \mathrm{al}^{64} / \\
2015\end{array}$ & $\begin{array}{l}\text { RCT in patients in the } \\
\text { medical ICU }(n=36)\end{array}$ & $\begin{array}{l}\text { Neuromuscular stimulation } \\
\text { applied to three lower } \\
\text { extremity muscle groups for } \\
60 \text { min compared with sham }\end{array}$ & $\begin{array}{l}\text { Greater walking distance, trend } \\
\text { toward increased muscle strength } \\
\text { according to MRC }\end{array}$ \\
\hline $\begin{array}{l}\text { Dirks et al }{ }^{65} / \\
2015\end{array}$ & $\begin{array}{l}\text { Prospective cohort study in } \\
\text { patients who were } \\
\text { comatose }(n=6)\end{array}$ & $\begin{array}{l}\text { Neuromuscular stimulation to } \\
\text { one leg twice daily for } 7 \text { days } \\
\text { compared with no stimulation }\end{array}$ & $\begin{array}{l}\text { No atrophy in stimulated leg, muscle } \\
\text { mRNA upregulation }\end{array}$ \\
\hline
\end{tabular}

6MWD = 6-min walk distance; RCT = randomized controlled trial; SF-36 = Short-Form 36. See Table 1 legend for expansion of other abbreviations.

independence (59\% vs $35 \% ; P=.02)$ and a greater walking distance at hospital discharge (33.4 vs $0 \mathrm{~m}$; $P=.004)$ for patients in the intervention group. ${ }^{62}$ There was a nonstatistically significant trend toward reductions in ICUAW $(P=.09)$, although the study was underpowered for this end point. ${ }^{62} \mathrm{~A}$ meta-analysis of the RCTs of early mobilization suggests it may be an effective treatment for ICUAW (pooled effect OR, 0.27; $P=.03){ }^{69}$

Patients who are critically ill rarely are mobilized, with studies suggesting that less than $10 \%$ of patients receiving mechanical ventilation receive out-of-bed mobility while in the ICU. ${ }^{70,71}$ Studies of in-bed cycling or direct muscle stimulation in patients who are comatose show promising results for reducing the burden of ICUAW, but these methods are still not proven effective. An RCT randomized 90 patients who were critically ill to a 30-minute session of cycle ergometry, either as passive cycling for patients who were comatose or active cycling for patients who were participating, or to standard rehabilitation care in the control group; results in the cycling group were greater walk distances and quadriceps force, with greater physical functioning quality-of-life scores at hospital discharge. ${ }^{60}$ Similarly, an RCT in 36 patients undergoing daily neuromuscular stimulation to the quadriceps, gastrocnemius, and tibialis anterior with a pulsed current and a biphasic, asymmetric, balanced rectangular waveform, with a ramp-up time of 2 seconds, ramp-down time of less than 1 second, and frequency (pulse rate) of $50 \mathrm{~Hz}$ resulted in longer 
walk distances and a trend toward increased muscle strength. ${ }^{64}$ Studies are needed to confirm these results in larger cohorts and to define better the appropriate timing, dosing, and frequency of cycle ergometry; functional neuromuscular stimulation; and ICU mobility for patients who are critically ill.

A number of ongoing trials are exploring potential preventive pharmacologic agents for ICUAW. These agents are primarily antiinflammatory or metabolic agents aimed at lessening the prevalence of ICUAW. Preventive therapies currently in active trials include serotonin 5-HT2C receptor agonists, hydroxymethylbutyrate and eicosapentaenoic acid, and intravenous immunoglobulin (NCT02523690, NCT01270516, NCT01867645).

Additional agents aimed at lessening the severity of ICUAW once present are also in drug development.

\section{Interventions Aimed at Treating ICUAW}

Once patients have developed ICUAW, it would be of use to know which interventions are most likely to restore previous function. Unlike other conditions associated with significant impairment-such as stroke, traumatic brain injury, or spinal cord injury-the exact type of rehabilitation interventions required to reduce impairment, maximize functional independence, and improve health-related quality of life are not yet well understood. To date, limited studies have evaluated intensive inpatient-based and outpatient rehabilitation programs.

One observational cohort study evaluating comprehensive inpatient rehabilitation in patients with CIM or CIP identified improvements in motor functional independence measures (mean increase from 45.6 to 69.7 ) and functional independence measures (mean increase from 78.7 to 103.3) between admission and discharge with mean stay of 67.4 days. ${ }^{72}$ Similarly, mean 6-minute walk test results improved from 77.3 to $291.5 \mathrm{~m}$, and mean 10-m walk test results improved from 1.5 to $2.4 \mathrm{~km} / \mathrm{h}$, but this study was limited by a lack of control subjects and overall methodologic quality. ${ }^{72}$ A 2010 RCT studying the effects of dedicated geriatric ward care on outcomes in elderly survivors of the medical ICU with unknown ICUAW status failed to demonstrate a significant difference in functional indexes (ie, Barthel index) after hospital discharge (75.6 vs $64.6 ; P=.2){ }^{73}$ An RCT of a home-based physical rehabilitation program with 195 participants also noted no significant effect in the SF-36 PFS or 6-minute walk test at 1,8 , or 26 weeks after hospital discharge, although this cohort was not restricted to patients who were weak. ${ }^{74}$ However, randomization to receipt of a 6-week self-help rehabilitation manual was associated significantly with improvements in the SF-36 PFS at 8 weeks and 6 months $(P=.006)$, with a trend toward a lower rate of depression at 8 weeks (12\% vs $25 \%)^{75}$

Randomized studies to date have not evaluated more comprehensive inpatient or outpatient rehabilitation programs employing occupational, physical, and speech or cognitive therapies; swallow evaluation; architectural accessibility and home modification; adaptive mobility and ADL devices; vocational rehabilitation; rehabilitation psychology; and therapeutic recreation. On the basis of models used for other conditions, ${ }^{76,77}$ it is likely that patients with physical and cognitive impairments following an ICU stay could benefit from comprehensive rehabilitation with interventions directed at addressing each of these domains. Additionally, it would be of use to evaluate the effect of these interventions on mortality, hospital readmission rates, required caregiving, health-related quality of life, and return to work or school.

\section{A Staged Approach to Classifying ICUAW}

Throughout this review, we have highlighted the heterogeneity of ICUAW, the difficulty with its routine diagnosis, and our current lack of effective therapies for reversing disease. Given these difficulties, we submit that a one-size-fits-all approach to diagnosing and treating ICUAW may not be an effective strategy. Although certain elements such as risk factor avoidance or modification potentially may be beneficial to all patients in the ICU, we suggest that, in general, assessments and interventions should target individualized stages of disease along the spectrum of dysfunction. Therefore, we propose the following theoretical framework (Fig 2) as a guide for future research on ICUAW.

Critical illness and recovery can be conceptualized as spanning four stages: stage 0 , pre-ICU: baseline functional assessment and prehospital trajectory; stage 1, early ICU: assessment of the patient who is not participatory; stage 2, late ICU: strength and function assessment; and stage 3, post-ICU: recovery assessment. Assessment modalities and instruments should be geared toward the targeted phase and potential patient participation. Interventions targeting ICUAW, alternatively, should not be restricted to a single stage, but rather stages should guide the development of interventions along the continuum. 


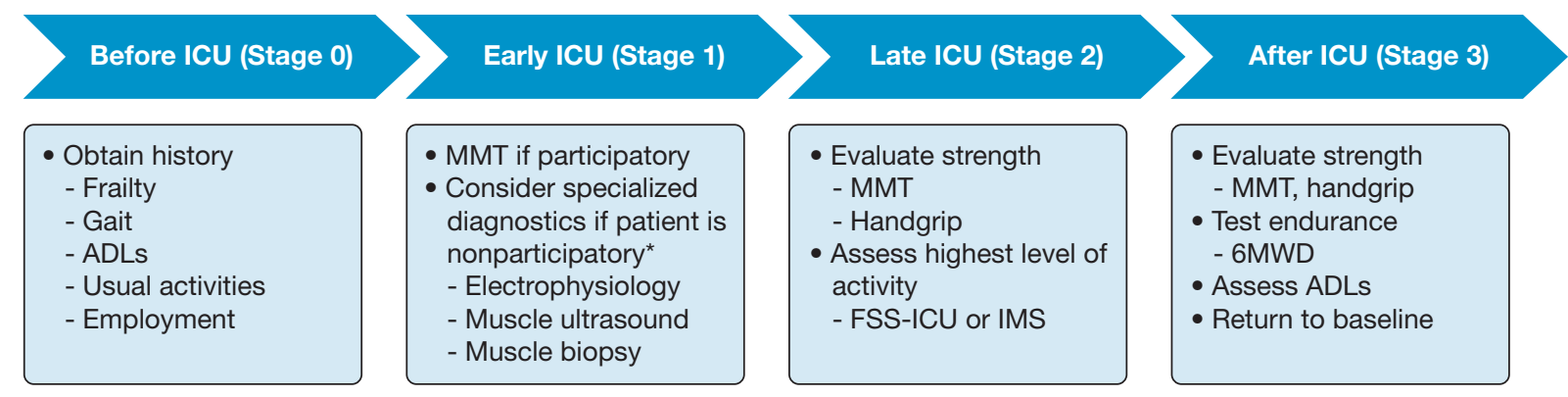

Figure 2 - Proposed staged approach to diagnosis and treatment of ICU-acquired weakness. $6 M W T=6$-min walk test; ADLs =activities of daily living; FSS-ICU = functional status score for the ICU; IMS = ICU Mobility Scale; MMT = manual muscle testing. ${ }^{*}$ Note that many patients in the ICU will remain participatory and skip stage 1. Also note that specialized diagnostics are not recommended as standard clinical practice but rather for research or for evaluation of distinct clinical questions.

The initial evaluation begins with a detailed baseline functional history. This stage focuses on in-depth understanding of the prehospital functional status. Key components of this functional history include data on basic and instrumental ADLs, locomotion status including fall history, employment or education, and cognitive status. This stage may use additional constructs, such as frailty, as a means of quantifying prehospital disability, functional trajectory, and resilience. Integrated electronic health record symptoms that allow for enhanced outpatient functional screening for the aforementioned domains may facilitate construction of detailed functional trajectories.

In the first stage of ICU assessment, many patients will be unable to participate. Clinicians should employ best practice methods for reducing delirium, including minimization of delirium-inducing medications, maintenance of sleep-wake cycles, and family engagement to optimize participation. Patients awake enough to participate should undergo strength testing by using a validated strength scale. Given the current lack of targeted therapy for ICUAW, further diagnostic testing may have limited clinical utility at this stage, and extensive diagnostics are not recommended as standard practice. ${ }^{78}$ However, patients with atypical clinical presentations for ICUAW (focal neurologic findings, distal weakness) or with underlying neurologic injury impacting strength testing may benefit from additional testing to exclude alternate causes or confirm the diagnosis of ICUAW (eg, patients with stroke or spinal cord disease who develop additional risk factors for ICUAW).$^{79}$ For research studies, we propose EP assessment, preferably using a single nerve protocol, early in the course of critical illness. Interventions at this time may include antiinflammatory or metabolic agents aimed at reducing neuromuscular injury, early risk factor modification to reduce severity of disease, and potentially cycle ergometry with functional electrical neuromuscular stimulation when active mobilization participation is not possible.

Once a patient is able to participate, assessments shift toward stage 2, focused on the delineation of newly acquired functional impairments so that a comprehensive rehabilitation plan can be designed. Strength can be assessed using validated, easy-to-use tests, including handgrip dynamometry and/or manual muscle strength testing. Global measures of strength at this time would include instruments created and validated for patients in the ICU such as the functional status score for the ICU (e-Appendix 1). The functional status score for the ICU is widely available (http://www. hopkinsmedicine.org/pulmonary/research/outcomes_ after_critical_illness_surgery/oacis_instruments.html), easy to administer, easy for the patient to complete, and responsive to change. ${ }^{80,81}$ Functional assessment should focus on the same domains as in stage 0-namely, basic and instrumental ADLs, ambulation status, and cognitive status. Interventions at this time should focus on addressing the identified strength or functional deficits and may include aggressive physical and occupational therapy interventions or anabolic interventions.

As a patient shifts into the recovery phase (stage 3 ) of critical illness, the intensity of global assessments increases. The Physical Function ICU Test (PFIT) was designed to measure strength, endurance, cardiovascular capacity, and functional level in patients who are critically ill. ${ }^{82,83}$ The PFIT correlates moderately with objective measures of muscle strength, including the Timed Up and Go test $(r=-0.6), 6$-minute walk test $(r=0.41)$, and MRC muscle test $(r=0.49)$ and is responsive to change in patients who are critically ill. ${ }^{82}$ In a cohort of 66 survivors of the ICU, the PFIT 
demonstrated excellent validity with MRC tested muscle strength $(r=0.8)$, was predictive of discharge to home, and demonstrated moderate responsiveness to change. ${ }^{81}$ At this point, interventions shift toward acceptance of newfound impairment while attempting to optimize function as much as possible. Further studies are needed to understand how factors associated with disability adaptation, including coping, mindfulness, and resiliency, or how alterations of the built or social environment impact recovery after critical illness. ${ }^{84,85}$

\section{Conclusions}

ICUAW is common in patients who are critically ill, often is underreported, and manifests in a spectrum of disease. Diagnostic limitations in our current testing modalities limit identification of weakness early in critical illness. Although illness severity, multiorgan failure, and immobilization are recognized as potential risk factors for ICUAW, the strength of these associations remains uncertain. Adjustment for baseline function may play an important role in understanding disease trajectories for ICUAW. To our knowledge, novel diagnostic methods, including single NCS and muscle ultrasound, may provide a minimally invasive means for early recognition of disease. Risk factor avoidance or modification and early activity may reduce the risk and severity of ICUAW. Studies are needed that explore interventions targeted toward patient participation and stage of disease rather than being applied uniformly across the spectrum.

\section{Acknowledgments}

Financial/nonfinancial disclosures: None declared.

Role of sponsors: The sponsor had no role in the design of the study, the collection and analysis of the data, or the preparation of the manuscript.

Additional information: The e-Appendix can be found in the Supplemental Materials section of the online article.

\section{References}

1. Osler W. The Principles and Practice of Medicine, Designed for the Use of Practitioners and Students of Medicine. New York: D. Appleton and Company; 1892.

2. Mertens HG. Disseminated neuropathy following coma. On the differentation of so-called toxic polyneuropathy. Nervenarzt. 1961;32:71-79.

3. Douglass JA, Tuxen DV, Horne M, et al. Myopathy in severe asthma. Am Rev Respir Dis. 1992;146(2):517-519.

4. Campellone JV, Lacomis D, Kramer DJ, Van Cott AC, Giuliani MJ. Acute myopathy after liver transplantation. Neurology. 1998;50(1): 46-53.

5. Bolton CF, Young GB, Zochodne DW. The neurological complications of sepsis. Ann Neurol. 1993;33(1):94-100.

6. De Jonghe B, Sharshar T, Lefaucheur JP, et al. Paresis acquired in the intensive care unit: a prospective multicenter study. JAMA. 2002;288(22):2859-2867.
7. Hermans G, Van Mechelen H, Bruyninckx F, et al. Predictive value for weakness and 1-year mortality of screening electrophysiology tests in the ICU. Intensive Care Med. 2015;41(12):2138-2148.

8. Moss M, Yang M, Macht M, et al. Screening for critical illness polyneuromyopathy with single nerve conduction studies. Intensive Care Med. 2014;40(5):683-690.

9. Batt J, dos Santos CC, Cameron JI, Herridge MS. Intensive care unitacquired weakness: clinical phenotypes and molecular mechanisms. Am J Respir Crit Care Med. 2013;187(3):238-246.

10. Bolton CF. Neuromuscular manifestations of critical illness. Muscle Nerve. 2005;32(2):140-163.

11. Witt NJ, Zochodne DW, Bolton CF, et al. Peripheral nerve function in sepsis and multiple organ failure. Chest. 1991;99(1):176-184.

12. Bolton CF, Brown JD, Sibbald WA. The electrophysiologic investigation of respiratory paralysis in critically ill patients. Neurology. 1983;33:186.

13. Latronico N, Bolton CF. Critical illness polyneuropathy and myopathy: a major cause of muscle weakness and paralysis. Lancet Neurol. 2011;10(10):931-941.

14. Helliwell TR, Wilkinson A, Griffiths RD, McClelland P, Palmer TE Bone JM. Muscle fibre atrophy in critically ill patients is associated with the loss of myosin filaments and the presence of lysosomal enzymes and ubiquitin. Neuropathol Appl Neurobiol. 1998;24(6): 507-517.

15. Stevens RD, Dowdy DW, Michaels RK, Mendez-Tellez PA, Pronovost PJ, Needham DM. Neuromuscular dysfunction acquired in critical illness: a systematic review. Intensive Care Med. 2007;33(11):1876-1891.

16. Hough CL, Lieu BK, Caldwell ES. Manual muscle strength testing of critically ill patients: feasibility and interobserver agreement. Crit Care. 2011;15(1):R43.

17. Connolly BA, Jones GD, Curtis AA, et al. Clinical predictive value of manual muscle strength testing during critical illness: an observational cohort study. Crit Care. 2013;17(5):R229.

18. Hermans G, Clerckx B, Vanhullebusch T, et al. Interobserver agreement of Medical Research Council sum-score and handgrip strength in the intensive care unit. Muscle Nerve. 2012;45(1):18-25.

19. Ali NA, O’Brien JM Jr, Hoffmann SP, et al. Acquired weakness, handgrip strength, and mortality in critically ill patients. Am J Respir Crit Care Med. 2008;178(3):261-268.

20. Latronico N, Nattino G, Guarneri B, et al. Validation of the peronea nerve test to diagnose critical illness polyneuropathy and myopathy in the intensive care unit: the multicentre Italian CRIMYNE-2 diagnostic accuracy study. F1000Res. 2014;3:127.

21. Wieske L, Verhamme C, Witteveen E, et al. Feasibility and diagnostic accuracy of early electrophysiological recordings for ICU acquired weakness: an observational cohort study. Neurocrit Care. 2015;22(3):385-394.

22. Bunnell A, Ney J, Gellhorn A, Hough CL. Quantitative neuromuscular ultrasound in intensive care unit-acquired weakness: a systematic review. Muscle Nerve. 2015;52(5):701-708.

23. Puthucheary ZA, Rawal J, McPhail M, et al. Acute skeletal muscle wasting in critical illness. JAMA. 2013;310(15):1591-1600.

24. Puthucheary ZA, Phadke R, Rawal J, et al. Qualitative ultrasound in acute critical illness muscle wasting. Crit Care Med. 2015;43(8): 1603-1611.

25. Fried LP, Ferrucci L, Darer J, Williamson JD, Anderson G. Untangling the concepts of disability, frailty, and comorbidity: implications for improved targeting and care. J Gerontol A Biol Sci Med Sci. 2004;59(3):255-263.

26. Baldwin MR, Reid MC, Westlake AA, et al. The feasibility of measuring frailty to predict disability and mortality in older medical intensive care unit survivors. J Crit Care. 2014;29(3):401-408.

27. Le Maguet P, Roquilly A, Lasocki S, et al. Prevalence and impact of frailty on mortality in elderly ICU patients: a prospective, multicenter, observational study. Intensive Care Med. 2014;40(5): 674-682.

28. Bagshaw SM, Stelfox HT, Johnson JA, et al. Long-term association between frailty and health-related quality of life among survivors of 
critical illness: a prospective multicenter cohort study. Crit Care Med. 2015;43(5):973-982.

29. Iwashyna TJ, Ely EW, Smith DM, Langa KM. Long-term cognitive impairment and functional disability among survivors of severe sepsis. JAMA. 2010;304(16):1787-1794.

30. Iwashyna TJ, Netzer G, Langa KM, Cigolle C. Spurious inferences about long-term outcomes: the case of severe sepsis and geriatric conditions. Am J Resp Crit Care Med. 2012;185(8):835-841.

31. de Letter MA, Schmitz PI, Visser LH, et al. Risk factors for the development of polyneuropathy and myopathy in critically ill patients. Crit Care Med. 2001;29(12):2281-2286.

32. Leijten FS, Harinck-de Weerd JE, Poortvliet DC, de Weerd AW. The role of polyneuropathy in motor convalescence after prolonged mechanical ventilation. JAMA. 1995;274(15):1221-1225.

33. Bednarik J, Vondracek P, Dusek L, Moravcova E, Cundrle I. Risk factors for critical illness polyneuromyopathy. J Neurol. 2005;252(3): 343-351.

34. Amaya-Villar R, Garnacho-Montero J, Garcia-Garmendia JL, et al. Steroid-induced myopathy in patients intubated due to exacerbation of chronic obstructive pulmonary disease. Intensive Care Med. 2005;31(1):157-161.

35. Bercker S, Weber-Carstens S, Deja M, et al. Critical illness polyneuropathy and myopathy in patients with acute respiratory distress syndrome. Crit Care Med. 2005;33(4):711-715.

36. Garnacho-Montero J, Madrazo-Osuna J, Garcia-Garmendia JL, et al. Critical illness polyneuropathy: risk factors and clinical consequences - a cohort study in septic patients. Intensive Care Med. 2001;27(8):1288-1296.

37. Kupfer Y, Namba T, Kaldawi E, Tessler S. Prolonged weakness after long-term infusion of vecuronium bromide. Ann Intern Med. 1992;117(6):484-486.

38. Lefaucheur JP, Nordine T, Rodriguez P, Brochard L. Origin of ICU acquired paresis determined by direct muscle stimulation. J Neurol Neurosurg Psychiatry. 2006;77(4):500-506.

39. Rudis MI, Guslits BJ, Peterson EL, et al. Economic impact of prolonged motor weakness complicating neuromuscular blockade in the intensive care unit. Crit Care Med. 1996;24(10):1749-1756.

40. Thiele RI, Jakob H, Hund E, et al. Critical illness polyneuropathy: a new iatrogenically induced syndrome after cardiac surgery? Eur J Cardiothorac Surg. 1997;12(6):826-835.

41. Hough CL, Steinberg KP, Taylor Thompson B, Rubenfeld GD, Hudson LD. Intensive care unit-acquired neuromyopathy and corticosteroids in survivors of persistent ARDS. Intensive Care Med. 2009;35(1):63-68.

42. Garnacho-Montero J, Amaya-Villar R, Garcia-Garmendia JL Madrazo-Osuna J, Ortiz-Leyba C. Effect of critical illness polyneuropathy on the withdrawal from mechanical ventilation and the length of stay in septic patients. Crit Care Med. 2005;33(2): 349-354.

43. Papazian L, Forel JM, Gacouin A, et al. Neuromuscular blockers in early acute respiratory distress syndrome. $N$ Engl J Med. 2010;363(12):1107-1116.

44. van den Berghe G, Wouters P, Weekers F, et al. Intensive insulin therapy in critically ill patients. $N$ Engl J Med. 2001;345(19): 1359-1367.

45. Mitchell KH, Carlbom D, Caldwell E, Leary PJ, Himmelfarb J, Hough CL. Volume overload: prevalence, risk factors, and functional outcome in survivors of septic shock. Ann Am Thorac Soc. 2015;12(12):1837-1844.

46. Parsons EC, Kross EK, Ali NA, et al. Red blood cell transfusion is associated with decreased in-hospital muscle strength among critically ill patients requiring mechanical ventilation. J Crit Care. 2013;28(6):1079-1085.

47. Convertino VA, Bloomfield SA, Greenleaf JE. An overview of the issues: physiological effects of bed rest and restricted physical activity. Med Sci Sports Exerc. 1997;29(2):187-190.

48. Kasper CE, Talbot LA, Gaines JM. Skeletal muscle damage and recovery. AACN Clin Issues. 2002;13(2):237-247.
49. Sargeant AJ, Davies CT, Edwards RH, Maunder C, Young A. Functional and structural changes after disuse of human muscle. Clin Sci Mol Med. 1977;52(4):337-342.

50. Kortebein P, Ferrando A, Lombeida J, Wolfe R, Evans WJ. Effect of 10 days of bed rest on skeletal muscle in healthy older adults. JAMA. 2007;297(16):1772-1774.

51. Topp R, Ditmyer M, King K, Doherty K, Hornyak J III. The effect of bed rest and potential of prehabilitation on patients in the intensive care unit. AACN Clin Issues. 2002;13(2):263-276.

52. Berg HE, Larsson L, Tesch PA. Lower limb skeletal muscle function after 6 wk of bed rest. J Appl Physiol. 1997;82(1):182-188.

53. Herridge MS, Cheung AM, Tansey CM, et al. One-year outcomes in survivors of the acute respiratory distress syndrome. $N$ Engl J Med. 2003;348(8):683-693.

54. Hermans G, Van Mechelen H, Clerckx B, et al. Acute outcomes and 1-year mortality of intensive care unit-acquired weakness: a cohort study and propensity-matched analysis. Am J Respir Crit Care Med. 2014;190(4):410-420

55. Sharshar T, Bastuji-Garin S, Stevens RD, et al. Presence and severity of intensive care unit-acquired paresis at time of awakening are associated with increased intensive care unit and hospital mortality. Crit Care Med. 2009;37(12):3047-3053.

56. Fan E, Dowdy DW, Colantuoni E, et al. Physical complications in acute lung injury survivors: a two-year longitudinal prospective study. Crit Care Med. 2014;42(4):849-859.

57. Wieske L, Dettling-Ihnenfeldt DS, Verhamme C, et al. Impact of ICU-acquired weakness on post-ICU physical functioning: a followup study. Crit Care. 2015;19:196.

58. Griffiths RD, Palmer TE, Helliwell T, et al. Effect of passive stretching on the wasting of muscle in the critically ill. Nutrition. 1995;11(5):428-432.

59. Hermans G, De Jonghe B, Bruyninckx F, Van den Berghe G. Interventions for preventing critical illness polyneuropathy and critical illness myopathy. Cochrane Database Syst Rev. 2009;(1): CD006832.

60. Burtin C, Clerckx B, Robbeets C, et al. Early exercise in critically ill patients enhances short-term functional recovery. Crit Care Med. 2009;37(9):2499-2505.

61. Morris PE, Goad A, Thompson C, et al. Early intensive care unit mobility therapy in the treatment of acute respiratory failure. Crit Care Med. 2008;36(8):2238-2243.

62. Schweickert WD, Pohlman MC, Pohlman AS, et al. Early physical and occupational therapy in mechanically ventilated, critically ill patients: a randomised controlled trial. Lancet. 2009;373(9678): 1874-1882.

63. Angelopoulos E, Karatzanos E, Dimopoulos S, et al. Acute microcirculatory effects of medium frequency versus high frequency neuromuscular electrical stimulation in critically ill patients - a pilot study. Ann Intensive Care. 2013;3(1):39.

64. Kho ME, Truong AD, Zanni JM, et al. Neuromuscular electrical stimulation in mechanically ventilated patients: a randomized, sham-controlled pilot trial with blinded outcome assessment. J Crit Care. 2015;30(1):32-39.

65. Dirks ML, Hansen D, van Assche A, et al. Neuromuscular electrical stimulation prevents muscle wasting in critically ill comatose patients. Clin Sci (Lond). 2015;128(6):357-365.

66. Bailey P, Thomsen GE, Spuhler VJ, et al. Early activity is feasible and safe in respiratory failure patients. Crit Care Med. 2007;35(1): $139-145$.

67. Morris PE, Griffin L, Berry M, et al. Receiving early mobility during an intensive care unit admission is a predictor of improved outcomes in acute respiratory failure. Am J Med Sci. 2011;341(5):373-377.

68. Needham DM, Korupolu R, Zanni JM, et al. Early physical medicine and rehabilitation for patients with acute respiratory failure: a quality improvement project. Arch Phys Med Rehabil. 2010;91(4): 536-542.

69. Kayambu G, Boots R, Paratz J. Physical therapy for the critically ill in the ICU: a systematic review and meta-analysis. Crit Care Med. 2013;41(6):1543-1554. 
70. Berney SC, Harrold M, Webb SA, et al. Intensive care unit mobility practices in Australia and New Zealand: a point prevalence study. Crit Care Resusc. 2013;15(4):260-265.

71. Nydahl P, Ruhl AP, Bartoszek G, et al. Early mobilization of mechanically ventilated patients: a 1-day point-prevalence study in Germany. Crit Care Med. 2014;42(5):1178-1186.

72. Novak P, Vidmar G, Kuret Z, Bizovičar N. Rehabilitation of critical illness polyneuropathy and myopathy patients: an observational study. Int J Rehabil Res. 2011;34(4):336-342.

73. Somme D, Andrieux N, Guerot E, et al. Loss of autonomy among elderly patients after a stay in a medical intensive care unit (ICU): a randomized study of the benefit of transfer to a geriatric ward. Arch Gerontol Geriatr. 2010;50(3):e36-e40.

74. Elliott D, McKinley S, Alison J, et al. Health-related quality of life and physical recovery after a critical illness: a multi-centre randomised controlled trial of a home-based physical rehabilitation program. Crit Care. 2011;15(3):R142.

75. Jones C, Skirrow P, Griffiths RD, et al. Rehabilitation after critical illness: a randomized, controlled trial. Crit Care Med. 2003;31(10): 2456-2461.

76. Klein MB, Lezotte DL, Fauerbach JA, et al. The National Institute on Disability and Rehabilitation Research burn model system database: a tool for the multicenter study of the outcome of burn injury. J Burn Care Res. 2007;28(1):84-96.

77. Parent S, Barchi S, LeBreton M, Casha S, Fehlings MG. The impact of specialized centers of care for spinal cord injury on length of stay, complications, and mortality: a systematic review of the literature. J Neurotrauma. 2011;28(8):1363-1370.
78. Fan E, Cheek F, Chlan L, et al. An official American Thoracic Society Clinical Practice guideline: the diagnosis of intensive care unitacquired weakness in adults. Am J Respir Crit Care Med. 2014;190(12):1437-1446.

79. Latronico N, Fenzi F, Recupero D, et al. Critical illness myopathy and neuropathy. Lancet. 1996;347(9015):1579-1582.

80. Thrush A, Rozek M, Dekerlegand JL. The clinical utility of the functional status score for the intensive care unit (FSS-ICU) at a long-term acute care hospital: a prospective cohort study. Phys Ther 2012;92(12):1536-1545.

81. Parry SM, Denehy L, Beach LJ, Berney S, Williamson HC, Granger CL. Functional outcomes in ICU: what should we be using? An observational study. Crit Care. 2015;19(1):127.

82. Denehy L, de Morton NA, Skinner EH, et al. A physical function test for use in the intensive care unit: validity, responsiveness, and predictive utility of the physical function ICU test (scored). Phys Ther. 2013;93(12):1636-1645.

83. Skinner EH, Berney S, Warrillow S, Denehy L. Development of a physical function outcome measure (PFIT) and a pilot exercise training protocol for use in intensive care. Crit Care Resusc. 2009;11(2):110-115.

84. Cox CE, Porter LS, Buck PJ, et al. Development and preliminary evaluation of a telephone-based mindfulness training intervention for survivors of critical illness. Ann Am Thorac Soc. 2014;11(2):173-181.

85. Iwashyna TJ, Netzer G. The burdens of survivorship: an approach to thinking about long-term outcomes after critical illness. Semin Respir Crit Care Med. 2012;33(4):327-338. 